\title{
Prevalence and Risk Factors of Helicobacter pylori Infection among Children Aged 1 to 15 Years at Holy Innocents Children's Hospital, Mbarara, South Western Uganda
}

\author{
Phoebe Aitila, ${ }^{1}$ Michael Mutyaba, ${ }^{1}$ Simon Okeny, ${ }^{1}$ Maurice Ndawula Kasule, ${ }^{1}$ \\ Rashid Kasule, ${ }^{1}$ Frank Ssedyabane, ${ }^{1}$ Benson Okongo $(\mathbb{D}){ }^{1}$ \\ Richard Onyuthi Apecu $\mathbb{D},{ }^{1}$ Enoch Muwanguzi, ${ }^{1}$ and Caesar Oyet $\mathbb{D}{ }^{1,2}$ \\ ${ }^{1}$ Mbarara University of Science and Technology, Faculty of Medicine, Department of Medical Laboratory Sciences, \\ P.O. Box 1410, Mbarara, Uganda \\ ${ }^{2}$ Clarke International University, Institute of Allied Health, P.O. Box 7782, Kampala, Uganda
}

Correspondence should be addressed to Caesar Oyet; caesaroyet@yahoo.com

Received 3 November 2018; Accepted 20 February 2019; Published 7 March 2019

Academic Editor: Marcel Tanner

Copyright (C) 2019 Phoebe Aitila et al. This is an open access article distributed under the Creative Commons Attribution License, which permits unrestricted use, distribution, and reproduction in any medium, provided the original work is properly cited.

Background. Helicobacter pylori infection affects more than half of the world's population. The infection is generally acquired during childhood but can remain asymptomatic, with long-term clinical sequelae including gastritis, peptic ulcer disease, and stomach cancer. Methods. The study was approved by Institutional Review Committee of Mbarara University of Science and Technology. After obtaining informed consent from parents/legal guardians, illegible children who presented with gastrointestinal complaints at Holy Innocents Children's Hospital were recruited; structured questionnaires were administered to the parents/guardians to collect information on sociodemographic data and risk factors of $H$. pylori infection. Four (4) millilitres of blood was collected from each child and tested for $H$. pylori blood Antibody test and stool specimens were used for $H$. pylori antigen test. Results. The prevalence of $H$. pylori infection among the study participants was $24.3 \%$. The infection rate increased with increase in age of the participants, from $16.2 \%$ among 1to 5 years old to $27.2 \%$ among 6 to 10 years. Infections were higher among school going children (68/74, p=0.003, OR 3.9; CI: 1.5 to 10.6) and children from crowded households (59/74, p<0.001, OR 2.6, and CI 1.3 to 5.0), unsafe source of drinking water at schools $(46 / 74, \mathrm{p}=0.003)$, and lack of sanitary facility at homes $(57 / 74, \mathrm{p}=0.001$, and OR $1.6 \mathrm{CI} 0.7$ to 3.6). Conclusion. The prevalence of $H$. pylori infection among children aged 1 to 15 years at Holy Innocents Children's Hospital was high and increases with age. School attendance, lack of sanitary facility, lack of safe drinking water, and overcrowding were the risk factors associated with $H$. pylori infection.

\section{Background}

Helicobacter pylori infection is a global public health problem, affecting over $50 \%$ of the population worldwide $[1,2]$. Infections are thought to occur early in life (during childhood) and the infection implicates several medical conditions including chronic gastritis, gastric cancer, gastric adenocarcinoma, mucosa-associated lymphoid tissue (MALT), lymphoma, and peptic ulcer disease [2-5]. Infected individuals present with gastric reflux, abdominal pain, intestinal bleeding, occasional fevers, and loss of weight which if not treated can result in gastric ulceration and perforation [6]. The incidence and prevalence rates of childhood infection with $H$. pylori vary greatly [5]. Within developed nations, prevalence rates of $H$. pylori infection among children have been shown to range from as low as $1.8 \%$ to as high as $65 \%$ [7-13]. While in developing countries the prevalence is generally higher reaching up to $90 \%$ in some countries [14-20]. The mode of transmission for $H$. pylori is not certainly known; however, epidemiological studies strongly support person-to-person transmission and fecal-oral and oral-oral routes [21-26]. School going children in developing countries 
TABLE 1: Demographic characteristics of the participants or parents/guardians $(n=304)$.

\begin{tabular}{|c|c|c|c|}
\hline Variable & Category & Frequency & Percentage \\
\hline Sex & Female & 162 & 53.3 \\
\hline \multirow[t]{3}{*}{ Age group } & 1 to 5 years & 130 & 42.8 \\
\hline & 6 to 10 years & 114 & 37.5 \\
\hline & 11 to 15 years & 60 & 19.7 \\
\hline \multirow[t]{4}{*}{ District of residence } & Mbarara & 170 & 55.9 \\
\hline & Kiruhura & 46 & 15.1 \\
\hline & Isingiro & 57 & 18.8 \\
\hline & Others & 31 & 10.2 \\
\hline School attendance & Yes & 242 & 79 \\
\hline \multirow[t]{4}{*}{ Source of drinking water at school } & Tap water & 164 & 53.9 \\
\hline & Borehole & 37 & 12.2 \\
\hline & Spring & 41 & 13.5 \\
\hline & Not applicable & 62 & 20.4 \\
\hline Presence of a hand washing & Yes & 194 & 63.8 \\
\hline \multirow[t]{2}{*}{ facility and toilet at school } & No & 50 & 16.4 \\
\hline & Not applicable & 60 & 19.7 \\
\hline \multirow[t]{4}{*}{ Education level of parent/guardian } & University & 161 & 53.0 \\
\hline & Secondary & 80 & 26.3 \\
\hline & Primary & 48 & 15.8 \\
\hline & No formal education & 15 & 4.9 \\
\hline
\end{tabular}

are at higher risk of $H$. pylori infection. Several factors control the transmission in developing countries including low socioeconomic status, poor quality of drinking water, overcrowding, poor personal and environmental hygiene, and food contamination [27-33]. In Uganda, data on the prevalence of $H$. pylori infection in children are scanty. Few studies have been reported in Kampala with an overall prevalence of $43.3 \%$ [20]. To the best of our knowledge, there is no available published information on the prevalence of H. pylori infection in children in South Western Uganda. The primary objective of this study was to determine the prevalence and risk factors of $H$. pylori infection among children at Holy Innocents Paediatric Hospital in Mbarara South Western Uganda.

\section{Method and Materials}

A cross-sectional study was conducted at Holy Innocents Children's Hospital. The study was approved by Research and Ethics committee of Mbarara University of Science and Technology. Informed consent was obtained from parents or legal guardians of the children before enrolment in the study.

2.1. Data Collection. A total of 304 participants aged 1 to 15 years who presented with gastrointestinal complaints were randomly recruited into the study from January 2017 to August 2017. The participants were recruited using simple randomization technique as described previously [34, 35]. Briefly, every child who presented with gastrointestinal complaints had a parent or legal guardian was requested to pick a number written on cards and place it in a box before the recruitment. Every parent or guardian who picked an even number is allowed to consent, and the child is enrolled. The cards were reshuffled each time a card is picked. A simple closed-ended questionnaire was then administered to collect information on age and gender of the participating child, type of home toilet facility, sources of drinking water at home, number of people in their household, number of siblings, family history of peptic ulcers, and the educational level of the parent/guardian. $4 \mathrm{mls}$ of venous blood was drawn from each participant into a plain vacutainer tube and processed for $H$. pylori antibodies using rapid antibody-antigen based immunoassay strips (ABON BIOPHARM HANGZHOU CO LTD, CHINA). Stool samples from those that tested positive with antibody test were subjected to Helicobacter pylori antigen in human fecal specimen test strip (Vaxpert Inc. suite 355 Two south Biscayne Blvd Miami, Fl, USA). A positive $H$. pylori test was defined as positive antigen test performed on the stool specimen.

2.2. Statistical Analysis. The data generated were coded, entered, validated, and analyzed using STATA 12 software (StataCorp, College Station, TX, USA). Associations between categorical variables were tested using the chi-squared test with reports of the corresponding p-values. In some instances where there were small numbers in a given cell $(<5)$, Fischer's exact test was used and the corresponding $\mathrm{p}$-value reported. The odds ratio and the corresponding 95\% confidence intervals (95\% CI) were used to summarize the strength of association between $H$. pylori seropositivity and risk factors in a multinomial logistic regression test. The level of statistical significance for the study was set at $\mathrm{p}<0.05$. In all the tests, p-values less than 0.05 or near 0.05 were used as statistical association $\mathrm{n}$ for risk factors of $H$. pylori infection. The outcome measure was the detection of the presence of $H$. pylori antigens in stool.

\section{Results}

3.1. Demographic Characteristics of the Children and Parents/Guardians. A total of 304 children aged 1 to 15 years were recruited in the study of which $53.3 \%$ were girls (Table 1 ). 


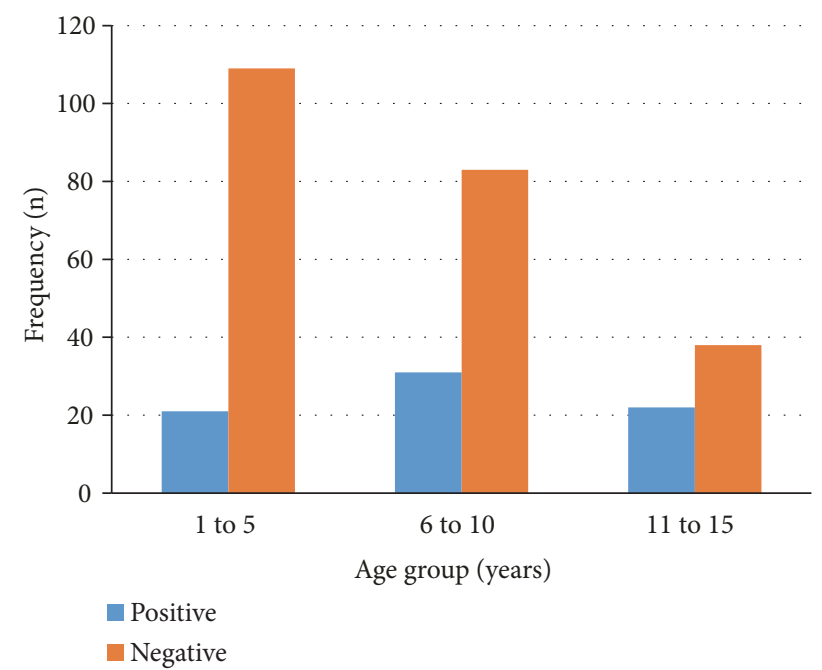

Figure 1: The distribution of $H$. pylori infection with age group (years) $n=304$.

The mean age of the children was 7 years with standard deviation of 4 years. Most of the children were 1 to 5 years old $(42.8 \%)$ and 6 to 10 years old $(37.5 \%)$ and the rest were older than 10 years. Majority of the children (79.6) were school going. More than half of the parents/guardians (53.0\%) had at least university education with a majority $(79.6 \%)$ living in permanent houses. Trade is the major activity of nearly half (49.3\%) of the parents/guardians.

3.2. Seroprevalence of $H$. pylori Infection. Up to 96 of the participants were positive for $H$. pylori antibody test. When the 96 antibody positive children were requested for stool samples, only was $24.3 \%$ ( 74 of 304 children) had positive antigen test. Therefore, the overall prevalence of $H$. pylori infection was $24.3 \%$.

The infection was highest among age group of 6 to 10 years $(n=31,41.9 \%)$ followed by the age group of 11 to 15 years $(n=22,29.7 \%)$ and lowest in the age group of 1 to 5 years $(n=21$, 28.4\%) (Figure 1). The distribution of $H$. pylori seropositivity with gender was roughly similar to $38(51.4 \%)$ of the cases in girls $(\mathrm{p}=0.2)$. Up to $68(91.9 \%)$ of seropositive H. pylori results were from school going children compared to $6(8.1 \%)$ in nonschool going children $(\mathrm{p}=0.003)$.

3.3. Factors Associated with H. pylori Infection. Several factors were studied about $H$. pylori seropositivity. The factors were gender, school attendance, sources of drinking water at schools and homes, the presence of hand washing sanitary facility at schools and homes, number of persons living in a home, family history of peptic ulcer disease and family history of stomach cancer (Tables 2 and 3). 36 out of 142 of the boys were $H$. pylori positive compared to 38 out of 124 of the girls $(\mathrm{p}=0.7)$. Majority of the infection occurred in children who attend schools compared to those who did not attend schools (68/174 vs $6 / 56, p=0.003)$. The infection rate was higher among children who had an unsafe source of water at their homes, had no sanitary facility at home, had overcrowded families or had an unsafe source of drinking water $(\mathrm{p}<0.001)$. Infection rate was seemingly similar among children who lacked sanitary facilities in their schools, had a family history of PUD or stomach cancer ( $p>0.001)$.

\section{Discussion}

The prevalence of the $H$. pylori infection was $24.3 \%$ among children aged 1 to 15 years among children attending Holy Innocents Hospital, Mbarara district. The prevalence in this study is low compared with findings from other studies among children in Kampala $[19,20]$ or different parts of Africa. However, our results are comparable to previous prevalence obtained in the neighbouring Kasese district where the prevalence of $H$. pylori was $29.9 \%$ [36]. The prevalence of $H$. pylori infection in other parts of Africa ranged between $40 \%$ and nearly $90 \%$ [37-41]. The low prevalence in our study would have been due to the recruitment of participants within a single or similar geographical characteristic. This would mean that some of the factors of transmission of $H$. pylori infection would be influenced by the environment $[25,31]$. The observed low prevalence in our study could also be due to the rising usage of antibiotics such as Amoxicillin and Metronidazole in Uganda in the management of many infections like gastrointestinal disorders. This practice could have led to increased clearance of $H$. pylori and the resulting lowered prevalence. Being periurban, our study participants have a higher social class, with better socioeconomic standards to avoid known transmission sources such as contaminated water and foods [16].

It is also important to note that the antigen used in the serum antibody test was not from African or Ugandan origin and this might have affected the sensitivity of the test. The effect of the antigen difference, however, would have been small to affect the quality of the results.

The prevalence of $H$. pylori infection increased with increase in age from $16.2 \%, 27.2 \%$, and $36.71 \%$ for children aged 1 to 5 years, 6 to 10 years, and 11 to 15 years, respectively. The trend is similar to what was demonstrated in others studies where infection rates increased with increase in age $[10,11$, $15,18,28,42-45]$. The finding would suggest that colonization with $H$. pylori organism starts early in life. During neonatal life, sources of infections would be limited to person to person from caretakers, family members, or nursery attendants. As age increase, exposure to various infection sources increases hence the ultimate rate of infection. This finding can explain why the rate of infection is higher in school going children. The rate of infection can even be higher in children who attend schools with no or poor sanitary facilities and or lack of clean drinking waters. Early study in Bangladesh found out that the rate of infection with $H$. pylori is lower in children 1 to 3 months but steadily increased from 6 to 9 months and in older children [5].

The current study has shown no difference of $H$. pylori infection rate in both girls and boys $\left(\mathrm{p}=0.7, \chi^{2}, 0.15\right)$. This suggests that maintaining all exposures constant, both girls and boys would be infected equally [46]. In this study the association of school attendance as a risk factor for $H$. pylori infection compared to nonschool attendance. This 
TABLE 2: Risk factors for H. pylori infection.

\begin{tabular}{|c|c|c|c|c|c|}
\hline \multirow{2}{*}{ variable } & & \multicolumn{2}{|c|}{ H. pylori result } & \multirow{2}{*}{ Chi square test } & \multirow{2}{*}{$P$ value } \\
\hline & & Positive & Negative & & \\
\hline \multirow{2}{*}{$\operatorname{sex}$} & Male & 36 & 106 & \multirow{2}{*}{0.15} & \multirow{2}{*}{0.7} \\
\hline & Female & 38 & 124 & & \\
\hline \multirow{2}{*}{ School attendance } & Yes & 68 & 174 & \multirow{2}{*}{9.05} & \multirow{2}{*}{0.003} \\
\hline & No & 6 & 56 & & \\
\hline \multirow{2}{*}{ Source of school drinking water } & Safe & 58 & 205 & \multirow{2}{*}{5.55} & \multirow{2}{*}{0.02} \\
\hline & Unsafe & 16 & 25 & & \\
\hline \multirow{2}{*}{ Sanitary facility at school } & Yes & 59 & 197 & \multirow{2}{*}{1.48} & \multirow{2}{*}{0.2} \\
\hline & No & 15 & 33 & & \\
\hline \multirow{2}{*}{ Sanitary facility at home } & Yes & 52 & 209 & \multirow{2}{*}{19.56} & \multirow{2}{*}{$<0.001$} \\
\hline & No & 22 & 21 & & \\
\hline \multirow{2}{*}{ Family history of PUD } & Yes & 39 & 101 & \multirow{2}{*}{1.74} & \multirow{2}{*}{0.2} \\
\hline & No & 35 & 129 & & \\
\hline \multirow{2}{*}{ Family history of cancer of stomach } & Yes & 21 & 67 & \multirow{2}{*}{0.02} & \multirow{2}{*}{0.9} \\
\hline & No & 53 & 163 & & \\
\hline \multirow{2}{*}{ Source of home drinking water } & Safe & 46 & 182 & \multirow{2}{*}{8.6} & \multirow{2}{*}{0.003} \\
\hline & Unsafe & 28 & 48 & & \\
\hline \multirow{2}{*}{ Overcrowding in the family } & Yes & 59 & 122 & \multirow{2}{*}{16.6} & \multirow{2}{*}{$<0.001$} \\
\hline & No & 15 & 108 & & \\
\hline
\end{tabular}

PUD: peptic ulcer disease.

TABle 3: Multinomial logistic regression showing associations between $H$. pylori infection and risk factors.

\begin{tabular}{|c|c|c|c|c|c|}
\hline Variable & Std. Err & Z score & Odds Ratio & $95 \% \mathrm{CI}$ & P value \\
\hline Sex & 0.338 & 0.48 & 1.151 & $0.647-2.045$ & 0.633 \\
\hline School attendance & 1.987 & 2.72 & 3.948 & $1.470-10.601$ & 0.006 \\
\hline Source of school drinking water & 0.423 & -0.13 & 0.944 & $0.393-2.270$ & 0.898 \\
\hline Sanitary facility at school & 0.678 & 1.05 & 1.574 & $0.676-3.664$ & 0.293 \\
\hline Source of drinking water at home & 0.193 & -1.70 & 0.549 & $0.275-1.094$ & 0.089 \\
\hline Sanitary facility at home & 0.089 & -3.76 & 0.228 & $0.106-0.492$ & $<0.001$ \\
\hline Family history of PUD & 0.570 & 1.72 & 1.751 & $0.925-3.314$ & 0.085 \\
\hline Family history of Ca Stomach & 0.263 & -0.87 & 0.731 & $0.361-1.481$ & 0.386 \\
\hline Family size & 0.872 & 2.84 & 2.597 & $1.344-5.016$ & 0.04 \\
\hline
\end{tabular}

Std. Err: standard error; CI: confidence interval; PUD: peptic ulcer disease; Ca stomach: cancer of the stomach.

suggests that, after commencing school, the poor hygiene at the schools increases the chance of infection with $H$. pylori bacteria. There is also concentration at schools increasing the chance of person-to-person transmission [47]. Person-toperson transmission can also occur at home as long as there is an infected person in the home for few months [48].

The study found a lower percentage of infection rate (4.9\%) among children from households with 1 to 3 members compared to $19.4 \%$ among children from households with more than 3 members $(\mathrm{p}<0.001)$. This would still mean that overcrowding increases chances of acquiring $H$. pylori infection in children [11, 47].

Examining the multivariate model, school attendance, family size, family history of PUD, and the absence of hand washing facility increased the chance of acquiring $H$. pylori infection, shown by ODDS Ratio $>1.0$ (Table 3 ). Since school attendance seems to be confounded upon by other unmeasured or measured factors, control of $H$. pylori infection would be geared towards eliminating other transmission points among school going children. The abovementioned ways of eliminating $H$. pylori infection can include improving the sanitation at schools and at homes, early diagnoses and treatments of the infected, and general community sensitization [49-51]. This finding however disagreed with early finding from a study among Bangladeshi children where lack of sanitary facilities was not associated with $H$. pylori infection [52].

\section{Conclusions}

The prevalence of $H$. pylori among children presenting with gastrointestinal complaints at Holy Innocents Children's Hospital is high. Risk factors $H$. pylori among children presenting with gastrointestinal complaints at Holy Innocents Children's Hospital were school attendance, lack of sanitary facility at 
schools and homes, and having more than overcrowding at homes.

\section{Data Availability}

The data is available on request from the corresponding author

\section{Conflicts of Interest}

The authors have no conflicts of interest to disclose.

\section{Authors' Contributions}

Phoebe Aitila, Michael Mutyaba, Simon Okeny, Maurice Ndawula Kasule, and Rashid Kasule conceived the research concept, planned the study, and collected the data; Caesar Oyet participated in statistical analysis; Frank Ssedyabane, Benson Okongo, and Caesar Oyet drafted the manuscript; Richard Onyuthi Apecu and Enoch Muwanguzi revised the manuscript. All authors proofread and accepted the content of the manuscript. These first authors, Phoebe Aitila, Michael Mutyaba, Simon Okeny, Maurice Ndawula Kasule, and Rashid Kasule, contributed equally to this article. These senior authors, Benson Okongo, Richard Onyuthi Apecu, Enoch Muwanguzi, and Caesar Oyet, contributed equally to this article.

\section{Acknowledgments}

The authors are so grateful to the parents/guardians and the children whom they enrolled for this study; without their acceptance, the study would have not been possible. They acknowledge the Hospital Director and all staff of Holy Innocents Children's Hospital who helped the team during data collection.

\section{References}

[1] A. Eshraghian, "Epidemiology of Helicobacter pylori infection among the healthy population in iran and countries of the eastern mediterranean region: a systematic review of prevalence and risk factors," World Journal of Gastroenterology: WJG, vol. 20, no. 46, pp. 17618-17625, 2014.

[2] M. Plummer, S. Franceschi, J. Vignat, D. Forman, and C. de Martel, "Global burden of gastric cancer attributable to Helicobacter pylori," International Journal of Cancer, vol. 136, no. 2, pp. 487-490, 2015.

[3] M. Kopáčová, J. Bureš, I. Koupil et al., "Body indices and basic vital signs in Helicobacter pylori positive and negative persons," European Journal of Epidemiology, vol. 22, no. 1, pp. 67-75, 2007.

[4] F. Sayehmiri, F. Kiani, K. Sayehmiri et al., "Prevalence of caga and vaca among helicobacter pylori-infected patients in iran: a systematic review and meta-analysis," The Journal of Infection in Developing Countries, vol. 9, no. 7, pp. 686-696, 2015.

[5] D. Mahalanabis, M. M. Rahman, S. A. Sarker et al., "Helicobacter pylori infection in the young in Bangladesh: Prevalence, socioeconomic and nutritional aspects," International Journal of Epidemiology, vol. 25, no. 4, pp. 894-898, 1996.
[6] D. S. Bordin, I. N. Voynovan, S. V. Kolbasnikov, and Y. V. Embutnieks, "Diagnosis of Helicobacter pylori infection in clinical practice," Terapevticheskii Arkhiv, vol. 90, no. 12, pp.133139, 2018.

[7] E. Roma and E. Miele, "Helicobacter pylori infection in pediatrics," Helicobacter, vol. 20, pp. 47-53, 2015.

[8] M. Okuda, T. Osaki, Y. Lin et al., "Low prevalence and incidence of helicobacter pylori infection in children: a population-based study in japan," Helicobacter, vol. 20, no. 2, pp. 133-138, 2015.

[9] F. Mana, S. Vandebosch, V. Miendje Deyi, P. Haentjens, and D. Urbain, "Prevalence of and risk factors for $\mathrm{H}$. pylori infection in healthy children and young adults in Belgium anno 2010/2011," Acta Gastro-Enterologica Belgica, vol. 76, no. 4, pp. 381-385, 2013.

[10] F. Carter, T. Seaton, Y. Yuan, and D. Armstrong, "Prevalence of helicobacter pylori infection in children in the bahamas," West Indian Medical Journal, vol. 61, no. 7, pp. 698-702, 2012.

[11] Z. Ding, S. Zhao, S. Gong et al., "Prevalence and risk factors of helicobacter pylori infection in asymptomatic chinese children: a prospective, cross-sectional, population-based study," Alimentary Pharmacology \& Therapeutics, vol. 42, no. 8, pp. 1019-1026, 2015.

[12] R. Llanes, L. M. Millán, M. P. Escobar et al., "Low prevalence of Helicobacter pylori among symptomatic children from a hospital in Havana, Cuba," Journal of Tropical Pediatrics, vol. 58, no. 3, pp. 231-234, 2012.

[13] H. M. Malaty, V. Paykov, O. Bykova et al., "Helicobacter pylori and socioeconomic factors in Russia," Helicobacter, vol. 1, no. 2, pp. 82-87, 1996.

[14] B. A. Salih, "Helicobacter pylori infection in developing countries: the burden for how long?" Saudi Journal of Gastroenterology, vol. 15, no. 3, pp. 201-207, 2009.

[15] F. Jaime, A. Villagrán, C. Serrano, J. Cerda, and P. R. Harris, "Frequency of helicobacter pylori infection in 144 school age chilean children," Revista Médica de Chile, vol. 141, no. 10, pp. 1249-1254, 2013.

[16] H.-L. Chen, M.-J. Chen, S.-C. Shih, H.-Y. Wang, I.-T. Lin, and M.-J. Bair, "Socioeconomic status, personal habits, and prevalence of helicobacter pylori infection in the inhabitants of Lanyu," Journal of the Formosan Medical Association= Taiwan yi zhi, vol. 113, no. 5, pp. 278-283, 2014.

[17] G. Ozbey, Y. Dogan, K. Demiroren, and I. H. Ozercan, "Prevalence of helicobacter pylori in children in eastern turkey and molecular typing of isolates," Brazilian Journal of Microbiology, vol. 46, no. 2, pp. 505-511, 2015.

[18] L. Ravelomanana, P. Imbert, N. Kalach et al., "Helicobacter pylori infection in children in Madagascar: risk factors for acquisition," Tropical gastroenterology: Official Journal of The Digestive Diseases Foundation, vol. 34, no. 4, pp. 244-251, 2013.

[19] J. Ankarklev, E. Hestvik, M. Lebbad et al., "Common coinfections of giardia intestinalis and helicobacter pylori in nonsymptomatic ugandan children," PLOS Neglected Tropical Diseases, vol. 6, no. 8, Article ID e1780, 2012.

[20] E. Hestvik, T. Tylleskar, D. H. Kaddu-Mulindwa et al., "Helicobacter pylori in apparently healthy children aged 0-12 years in urban kampala, uganda: a community-based cross sectional survey," BMC Gastroenterology, vol. 10, article 62, 2010.

[21] A. Sethi, M. Chaudhuri, L. Kelly, and W. Hopman, "Prevalence of helicobacter pylori in a first nations population in Northwestern Ontario," Canadian Family Physician, vol. 59, no. 4, pp. e182-e187, 2013. 
[22] Y. Urita, T. Watanabe, N. Kawagoe et al., "Role of infected grandmothers in transmission of Helicobacter pylori to children in a Japanese rural town," Journal of Paediatrics and Child Health, vol. 49, no. 5, pp. 394-398, 2013.

[23] K. F. Boehnke, K. A. Eaton, M. Valdivieso, L. H. Baker, and C. $\mathrm{Xi}$, "Animal model reveals potential waterborne transmission of helicobacter pylori infection," Helicobacter, vol. 20, no. 5, pp. 326-333, 2015.

[24] V. Singh, B. Trikha, K. Vaiphei, C. K. Nain, K. Thennarasu, and K. Singh, "Helicobacter pylori: evidence for spouse-to-spouse transmission," Journal of Gastroenterology and Hepatology, vol. 14, no. 6, pp. 519-522, 1999.

[25] E. V. Hastings, Y. Yasui, P. Hanington, and K. J. Goodman, "Community-driven research on environmental sources of $\mathrm{H}$. pylori infection in arctic Canada," Gut Microbes, vol. 5, no. 5, pp. 606-617, 2015.

[26] D. Sgambato, G. Visciola, E. Ferrante et al., "Prevalence of helicobacter pylori infection in sexual partners of $\mathrm{H}$. pyloriinfected subjects: role of gastroesophageal reflux," United European Gastroenterology Journal, vol. 6, no. 10, pp. 1470-1476, 2018.

[27] L. Tsongo, J. Nakavuma, C. Mugasa, and E. Kamalha, "Helicobacter pylori among patients with symptoms of gastroduodenal ulcer disease in rural Uganda," Infection Ecology \& Epidemiology, vol. 5, no. 1, Article ID 26785, 2015.

[28] O. Yucel, "Prevention of helicobacter pylori infection in childhood," World Journal of Gastroenterology, vol. 20, no. 30, pp. 10348-10354, 2014.

[29] F. A. Andoulo, D. N. Noah, M. Tagni-Sartre, E. C. N. Ndam, and K. N. Blackett, "Epidemiology of infection helicobacter pylori in Yaoundé: specificity of the african enigma," The Pan African Medical Journal, vol. 16, p. 115, 2013.

[30] S. I. Becker, R. D. Smalligan, J. D. Frame et al., "Risk of Helicobacter pylori infection among long-term residents in developing countries," The American Journal of Tropical Medicine and Hygiene, vol. 60, no. 2, pp. 267-270, 1999.

[31] W. Abebaw, M. Kibret, and B. Abera, "Prevalence and risk factors of $\mathrm{H}$. pylori from dyspeptic patients in Northwest Ethiopia: a hospital based cross-sectional study," Asian Pacific Journal of Cancer Prevention, vol. 15, no. 11, pp. 4459-4463, 2014.

[32] T.-L. Yan, Q.-D. Hu, Q. Zhang, Y.-M. Li, and T.-B. Liang, "National rates of helicobacter pylori recurrence are significantly and inversely correlated with human development index," Alimentary Pharmacology \& Therapeutics, vol. 37, no. 10, pp. 963-968, 2013.

[33] M. F. Go, "Review article: natural history and epidemiology of Helicobacter pylori infection," Alimentary pharmacology \& Therapeutics, vol. 16, 1, pp. 3-15, 2002.

[34] M. Setia, "Methodology series module 5: sampling strategies," Indian Journal of Dermatology, vol. 61, no. 5, pp. 505-509, 2016.

[35] W. Liu, L. Wang, and M. Yi, "Simple-random-sampling-based multiclass text classification algorithm," The Scientific World Journal, vol. 2014, Article ID 517498, 7 pages, 2014.

[36] L. Tsongo, J. Nakavuma, C. Mugasa, and E. Kamalha, Infection Ecology \& Epidemiology, vol. 5, 2015.

[37] A. N. Kimang'a, G. Revathi, S. Kariuki, S. Sayed, and S. Devani, "Helicobacter pylori: Prevalence and antibiotic susceptibility among Kenyans," South African Medical Journal, vol. 100, no. 1, pp. 53-57, 2010.

[38] M. A. Sathar, E. Gouws, A. E. Simjee, and A. M. Mayat, "Seroepidemiological study of Helicobacter pylori infection in South African children," Transactions of the Royal Society of Tropical Medicine and Hygiene, vol. 91, no. 4, pp. 393-395, 1997.
[39] S. Cherian, D. Forbes, F. Sanfilippo, A. Cook, and D. Burgner, "The epidemiology of Helicobacter pylori infection in African refugee children resettled in Australia," Medical Journal of Australia, vol. 189, no. 8, pp. 438-441, 2008.

[40] S. Cherian, D. P. Burgner, C. F. Carson, F. M. Sanfilippo, A. G. Cook, and D. A. Forbes, "Diagnosis of helicobacter pylori infection in a high-prevalence pediatric population: A comparison of 2 fecal antigen testing methods and serology," Journal of Pediatric Gastroenterology and Nutrition, vol. 47, no. 2, pp. 130-135, 2008.

[41] S. Cherian, D. Forbes, F. Sanfilippo, A. Cook, and D. Burgner, "Helicobacter pylori, helminth infections and growth: a crosssectional study in a high prevalence population," Acta Paediatrica, vol. 98, no. 5, pp. 860-864, 2009.

[42] K. Muhsen, M. Jurban, S. Goren, and D. Cohen, "Incidence, age of acquisition and risk factors of Helicobacter pylori infection among Israeli Arab infants," Journal of Tropical Pediatrics, vol. 58, no. 3, pp. 208-213, 2012.

[43] J. Bastos, B. Peleteiro, H. Pinto et al., "Prevalence, incidence and risk factors for Helicobacter pylori infection in a cohort of Portuguese adolescents (EpiTeen)," Digestive and Liver Disease: Official Journal of the Italian Society of Gastroenterology and the Italian Association for the Study of the Liver, vol. 45, no. 4, pp. 290-295, 2013.

[44] A. F. Syam, M. Miftahussurur, D. Makmun, and ETAL, "Risk factors and prevalence of Helicobacter pylori in five largest islands of Indonesia: A preliminary study," PLOS ONE, vol. 10, no. 11, Article ID e0140186, 2015.

[45] M. Hasosah, M. Satti, A. Shehzad et al., "Prevalence and risk factors of helicobacter pylori infection in saudi children: a three-year prospective controlled study," Helicobacter, vol. 20, no. 1, pp. 56-63, 2015.

[46] E. Tadesse, D. Daka, D. Yemane, and T. Shimelis, "Seroprevalence of Helicobacter pylori infection and its related risk factors in symptomatic patients in southern Ethiopia," BMC Research Notes, vol. 7, no. 834, 2014.

[47] H. Miyaji, T. Azuma, S. Ito et al., "Helicobacter pylori infection occurs via close contact infected individuals in early childhood," Journal of Gastroenterology and Hepatology, vol. 15, no. 3, pp. 257-262, 2000.

[48] H. Honma, Y. Nakayama, S. Kato et al., "Clinical features of Helicobacter pylori antibody-positive junior high school students in Nagano Prefecture, Japan," Helicobacter, Article ID e12559.

[49] A. Federico, A. G. Gravina, A. Miranda, C. Loguercio, and M. Romano, "Eradication of Helicobacter pyloriinfection: which regimen first?" World Journal of Gastroenterology, vol. 20, no. 3, pp. 665-672, 2014.

[50] L. M. Brown, T. L. Thomas, J.-L. Ma et al., "Helicobacter pylori infection in rural China: Demographic, lifestyle and environmental factors,' International Journal of Epidemiology, vol. 31, no. 3, pp. 638-646, 2002.

[51] P. Moayyedi, A. T. R. Axon, R. Feltbower et al., "Relation of adult lifestyle and socioeconomic factors to the prevalence of Helicobacter pylori infection," International Journal of Epidemiology, vol. 31, no. 3, pp. 624-631, 2002.

[52] J. Clemens, M. J. Albert, M. Rao et al., "Sociodemographic, hygienic and nutritional correlates of helicobacter pylori infection of young Bangladeshi children," The Pediatric Infectious Disease Journal, vol. 15, no. 12, pp. 1113-1118, 1996. 


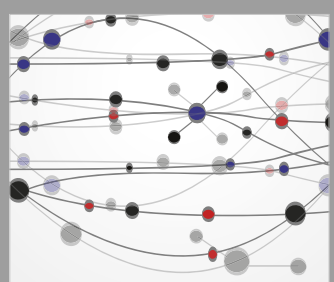

The Scientific World Journal
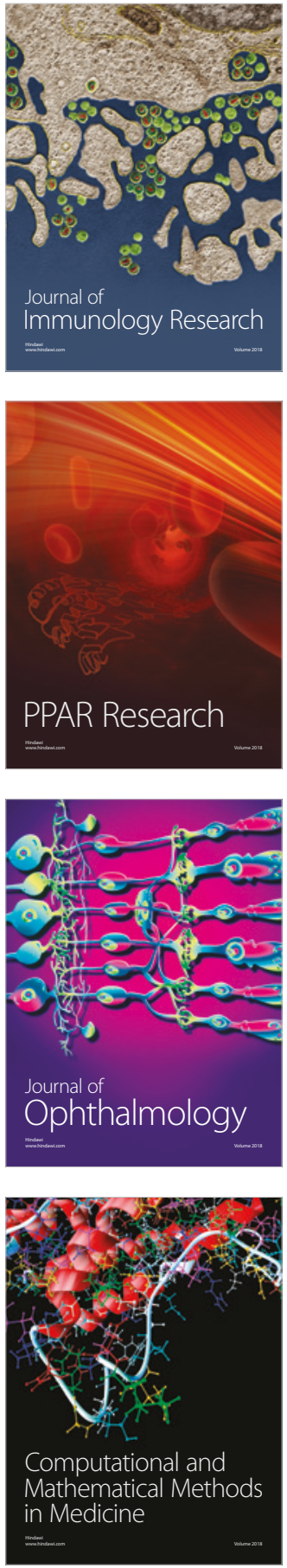

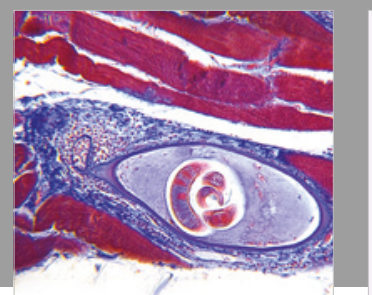

Gastroenterology Research and Practice

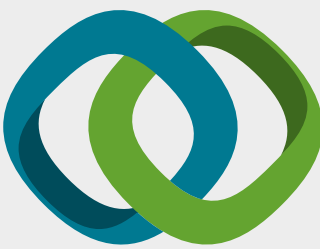

\section{Hindawi}

Submit your manuscripts at

www.hindawi.com
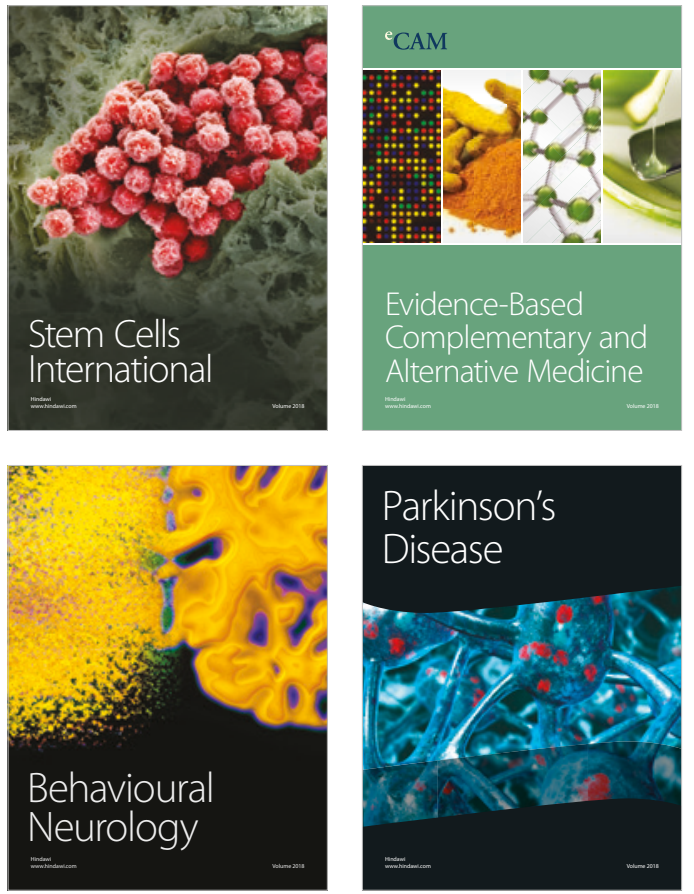

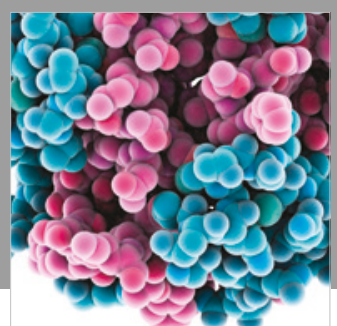

ournal of

Diabetes Research

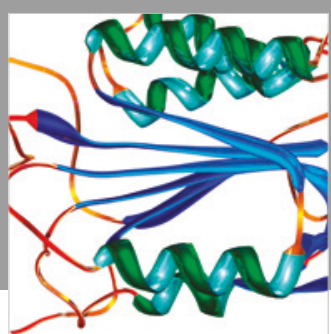

Disease Markers
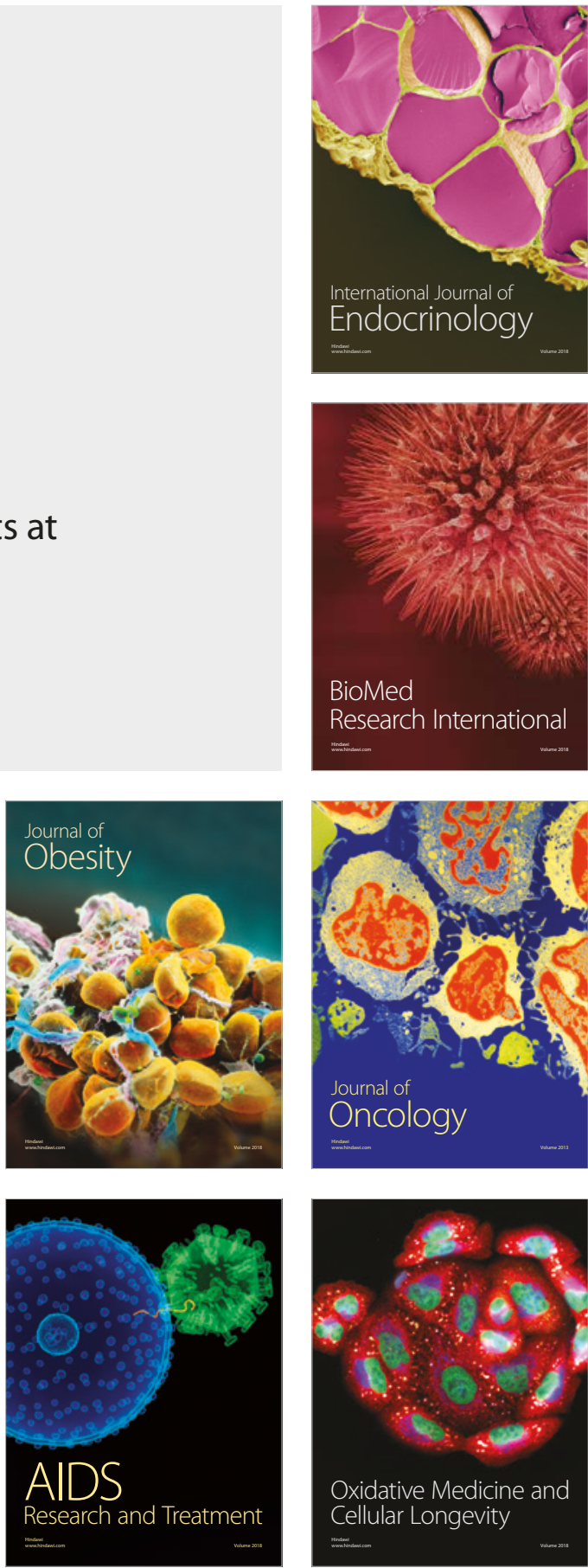